\title{
ASSESSMENT OF PEDESTRIAN MOBILITY ON ROAD NETWORKS IN THE CITY OF KIGALI
}

\section{DAVID NKURUNZIZAAND DR. RAHMAN TAFAHOMI}

(Received 28 July 2020; Revision Accepted 22 August 2020)

\begin{abstract}
This paper analyzed and assessed the pedestrians' mobility issues that are affecting their free movement and safety in the City of Kigali by outlining the major challenges in the City and providing alternative solutions and measures for improving the mobility and safety of pedestrians. The methodology of the paper was designed based on qualitative method with application of structured and unobtrusive. Referring to the paper findings about the mobility challenges of pedestrians within the City of Kigali, it is noted that the mobility of the pedestrians and their safety is still low and typical problems including road crossing viewed as the second challenges about pedestrians mobility, walking along very close to the road networks due to insufficient footpaths, lacking of enough road signs, lacking of information about pedestrian behavior on road networks, and improper functioning of existing traffic signals as the first challenge. The paper found that the majority of road networks in the City of Kigali did not provide walkways, traffics signals designs and availability is very poor and some of them not functioning, zebra crossing facilities were not provided adequately, pedestrians shelter on bus stop are almost absent and ignored, vehicles travelling speed is still high and does not allow pedestrians to move freely, and the mobility of physically challenged people has been forgotten and there is a need of introducing the pedestrian overpass bridges in clouded zones of the city center, Nyabugogo, Kicukiro and Remera-Giporoso areas of the City of Kigali.
\end{abstract}

KEYWORDS: Mobility, Pedestrian Safety, Road Networks, Traffic Signals, Pedestrians.

\section{INTRODUCTION}

\subsection{Overview}

The growth of the city should be hand in hand with the development of the transportation facilities for easing the movement of people and goods from one part of the city to another.
According to the Kigali City Master plan 2013, the road network in the city was supposed to be developed to fully meet the requirements of a modern city that is promoting the standard quality of life for its residents.

The City of Kigali is actually doing good to improve the existing road networks in various projects specifically in

David Nkurunziza, Department of Civil Environment and Geomatics Engineering, School of Engineering,

College of Science and Technology, University of Rwanda

Rahman Tafahomi, Senior Lecturer, Department of Architecture, School of Architecture and Built Environment, College of Science and Technology, University of Rwanda 
a project termed as Kigali Urban Road Upgrading Project where road network widening and traffic management by means of non-signalized and signalized junctions with traffic lights were implemented since 2016 till now. It is therefore important to upgrade and revitalize existing major master plan road networks for vehicles. Surprisingly however very little has been implemented for the city pedestrian in the matter of their crossing facilities.

This paper sought to examine the constraints faced by the Kigali City pedestrians on the road networks around the city at various critical locations mostly characterized by the accidents at Nyabugogo, Kicukiro, RemeraGiporoso and city center roads. The study was carried out to identify the possible mobility challenges and establish technical proposals to overcome the matter for the safety of residents.

\subsection{LITERATURE}

According to Peter Wright (2012), the pedestrian safety should be promoted by awakening both pedestrians and drivers about the importance of acting safely in all traffic environments by using and providing pedestrians' facilities appropriately.

Mariya et al. (2013) observed that pedestrians on Delhi roads are often exposed to high risks. This is because the basic needs of pedestrians are not recognized as a part of the urban transport infrastructure improvement projects in India. Also Dulaski and Liu (2013) discussed that the interaction between the pedestrian and vehicular driver at un-signalized mid-block locations when pedestrian is waiting at curb and stepping off the curb, the driver yield behavior is more when the pedestrian steps off from the curb and it is more during morning peak hours. However, Charles, (2010) said that the best way of teaching the pedestrians how to use road is by using communication designs which can facilitate their mobility. Dyaz (2002) highlighted that there is less likely risk to cross a roadway in the presence of motor vehicles in an urban area than rural area due to different design speeds.

Holland and Hill (2010) collected adult pedestrian accident data which demonstrated that the risk of being killed or seriously injured varied with age and gender. With increasing age, women were shown to make more unsafe mobility like crossing decisions, to leave small safety margins and to become poorer at estimating their walking speed. However, the age effects on all of these were ameliorated by driving experience. Men differed from women in that age was not a major factor in predicting unsafe pedestrians' mobility.

Zhuang and Wu (2011) studied that pedestrian's mobility, crossing out of crosswalks (unmarked roadway) and those crosswalks contributed much to traffic accidents, so the safety of pedestrians would be more in danger if not provided.

Granie and Brenac (2014) wrote about pedestrian behavior of being strongly dependent on biological gender, and it has also been found to depend on the psychological masculinity of an individual. Pedestrian speeds are also significantly related to pedestrian age, and the speeds of pedestrians are slower as they get older. Pedestrians especially old ones continue to develop their physical, cognitive and psychosocial abilities to cross the road network (Lim, 2008).

According to Ahmad et al. (2014), Consideration of the safety aspect is recommended for design of crossing facilities like signal at locations where female or old pedestrians are substantial to cross.

\section{MATERIALS AND METHOD}

This paper analyzed the problems faced by pedestrians in the City of Kigali, looked at their needs, existing infrastructure to facilitate them and adequate measures that would be taken to improve their mobility and safety. The methodology of this paper was designed based on the qualitative methods (Groat \& Wang, 2002; Neuman, 2006) with application of observation technique specifically the structured observation (Miller, et al., 2004; Marshall \& Rossman, 2006; Tafahomi \& Nadi, 2016) and the unobtrusive (Bonnes \& Bonaiuto, 2002; Tafahomi \& Nadi, 2020), which applied in the urban spaces and in a sensitive areas to study human behaviors. The descriptive approach was selected to explain the observation through storytelling (Groat \& Wang, 2002) and then analysis based on the collected for a period of three months.

The methodology adopted to conduct this research was descriptive research design by field observations on the selected road networks of the City of Kigali selected randomly within three Districts of Nyarugenge, Kicukiro and Gasabo. A field data collection and checking of six working days including Saturdays for the entire period of three months was used for the whole selected road samples where some forms were developed and filled accordingly by various categories of pedestrians and 
drivers on selected sites.

The Primary data included the field data collection for pedestrian spot point's prone areas to accidents, crossing location without facilities identified and interviewed to experts and some pedestrians to get their views. The following are pedestrian needs parameters that were assessed and include the Crosswalks (Zebra crossings and over bridges),sidewalks (Paved ways and unpaved ways),Warning marks, Shelters, Road Visibility,
Density of pedestrians, Traffic lights.

\section{RESULTS}

From data collection the following were pedestrian needs that were assessed and included crosswalks (Zebra crossings and over bridges), sidewalks (Paved ways and over bridges), Warning marks, buses shelters, road visibility, density of pedestrians, traffic lights availability. Also the existing facilities were noted down for

further

comparison.

Table 1: List of Assessed Roads within the City of Kigali

\begin{tabular}{|c|c|c|c|}
\hline $\mathbf{S} / \mathbf{N}$ & Name of Assessed Roads & $\mathbf{S} / \mathbf{N}$ & Name of Assessed Roads \\
\hline 1 & $\begin{array}{l}\text { City center } \quad(\text { KN1- } \\
\text { [KN3Rd] }\end{array}$ & 10 & Mukanogo - Nyabugogo [KN7Rd] \\
\hline 2 & $\begin{array}{l}\text { Remera - Kabeza }- \text { Rubirizi } \\
\text { [KK18Ave] }\end{array}$ & 11 & Nyabugogo Taxi Park - Gitikinyoni \\
\hline 3 & $\begin{array}{l}\text { Kigali Convention center - City } \\
\text { center [KN5Rd] }\end{array}$ & 12 & Zindiro - Chez Lando \\
\hline 4 & $\begin{array}{l}\text { Kigali City center Nyamirambo } \\
\text { [KN2Ave ] }\end{array}$ & 13 & Kigali Convention Centre - Nyabugogo [KG7Ave], [KN8Ave] \\
\hline 5 & $\begin{array}{l}\text { Nyamirambo } \quad-\quad \text { Nyarurama } \\
\text { [KN9Ave] }\end{array}$ & 14 & Sonatube - Kicukiro Nyanza Park [KN15Rd] \\
\hline 6 & $\begin{array}{l}\text { Nyamirambo } \quad-\quad \text { Nyabugogo } \\
\text { [KN20Ave] }\end{array}$ & 15 & Rwandex - Kicukiro Center [KK8Ave] \\
\hline 7 & $\begin{array}{l}\text { KN1 Roundabout - Nyabugogo } \\
\text { [KN1Rd] }\end{array}$ & 16 & $\begin{array}{l}\text { Kimironko Taxi Park - RBC \& Airtel Rwanda Head Quarter } \\
\text { [KG17Ave] }\end{array}$ \\
\hline 8 & Remera - Kimironko & 17 & Remera - Murindi [KK3Rd] \\
\hline 9 & Kigali City Center roads & 18 & Kanogo- Gikondo [KK2Ave], [KK4Ave] \\
\hline
\end{tabular}




\subsection{Zebra Crossing Facilities}

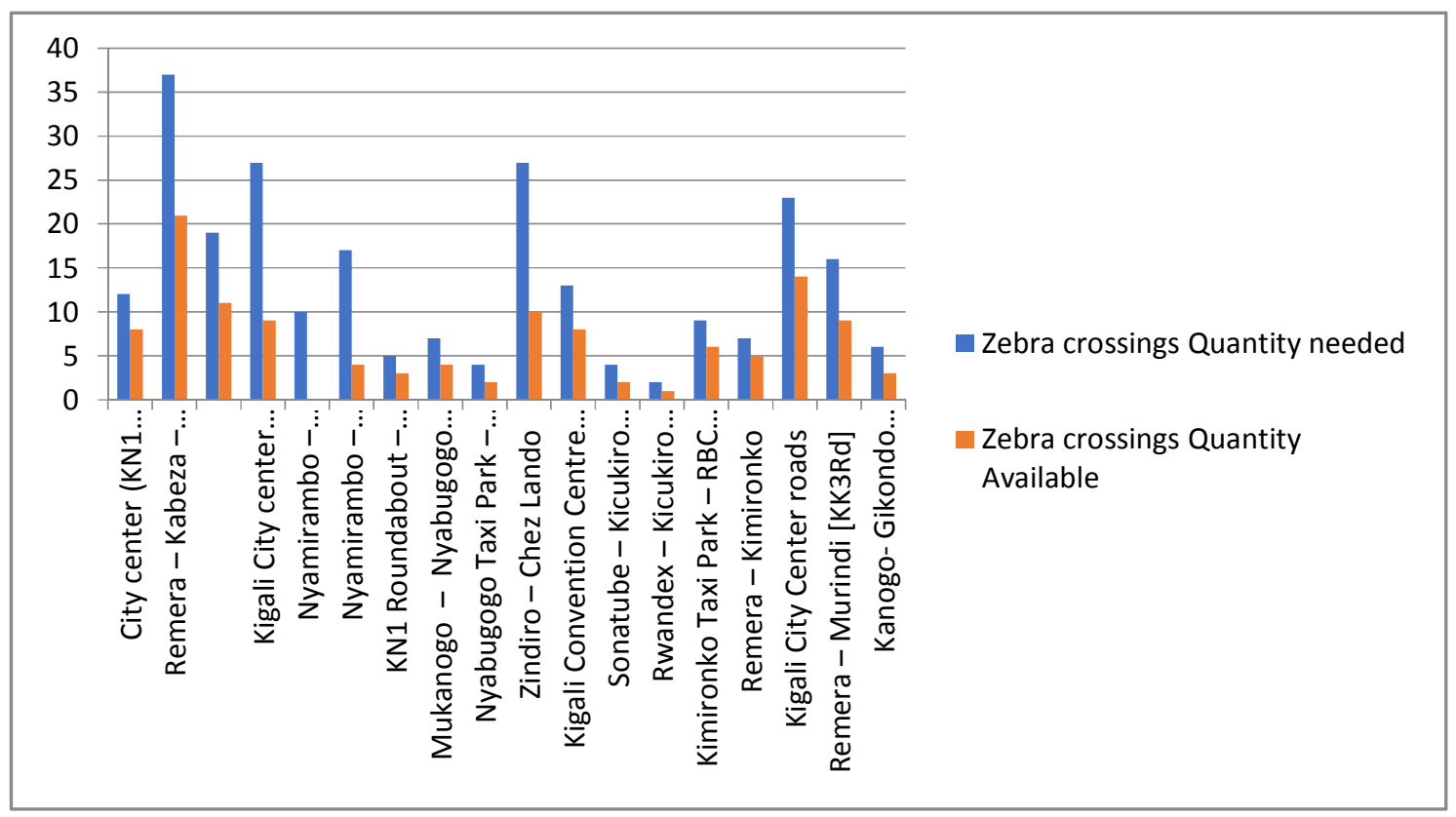

Figure 2: Comparison between Available and Needed Pedestrian Crossing facilities

\subsection{Traffic Lighting Facilities}

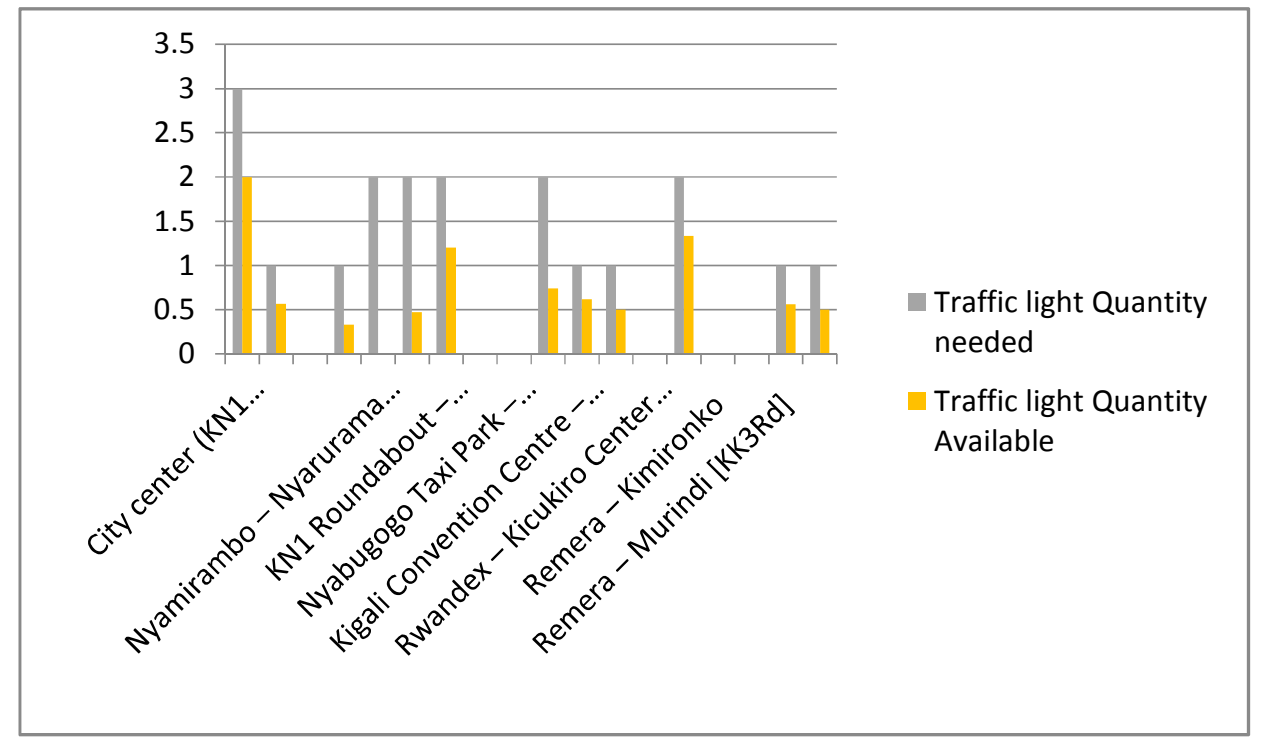

Figure 3: Comparison between Available and Needed Traffic Lighting Facilities 


\subsection{Pedestrian Bridge Facilities}

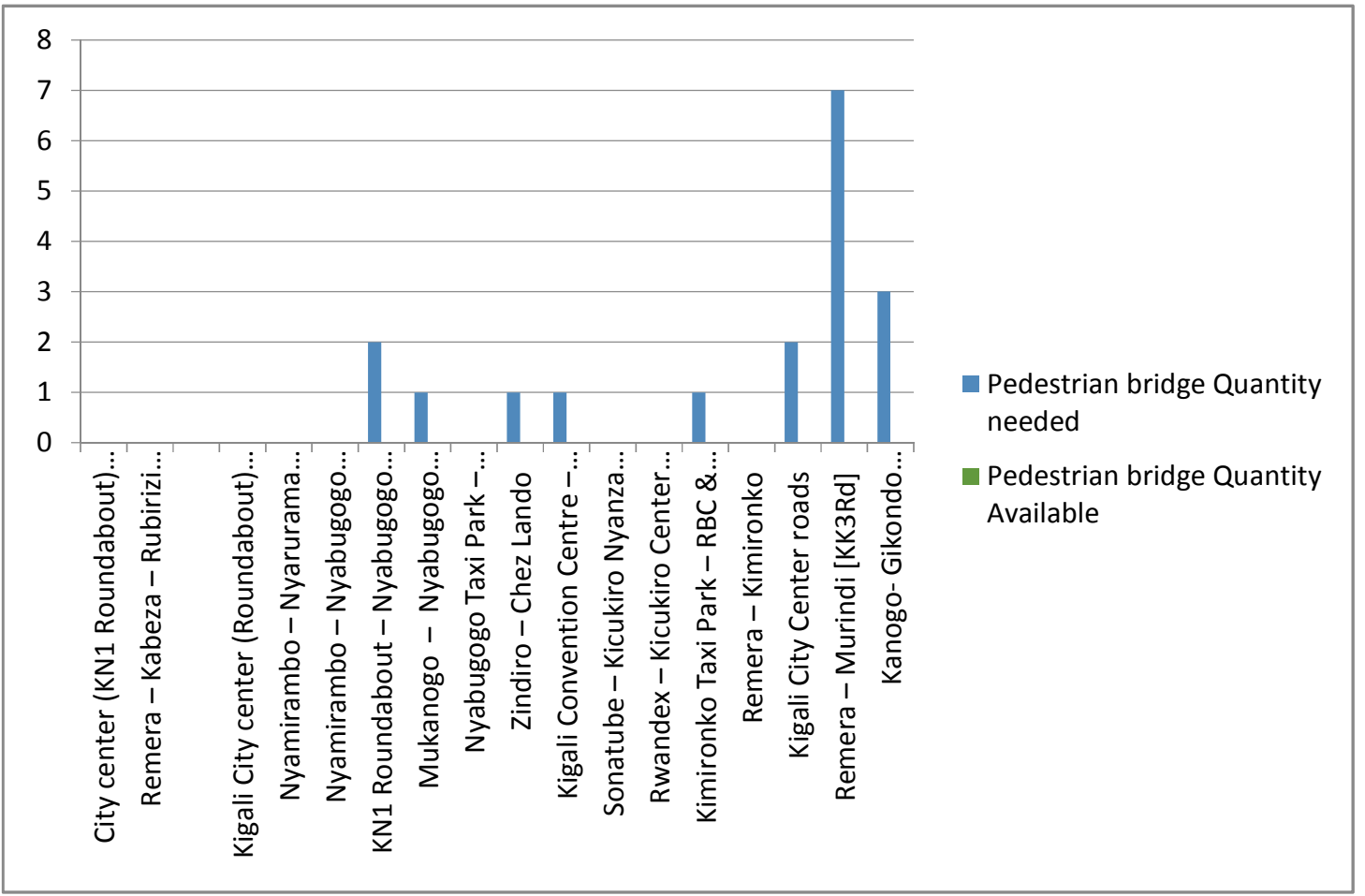

Figure 4: Comparison between Available and Needed Pedestrian Bridge Facilities

\subsection{Warning Signs Facilities}

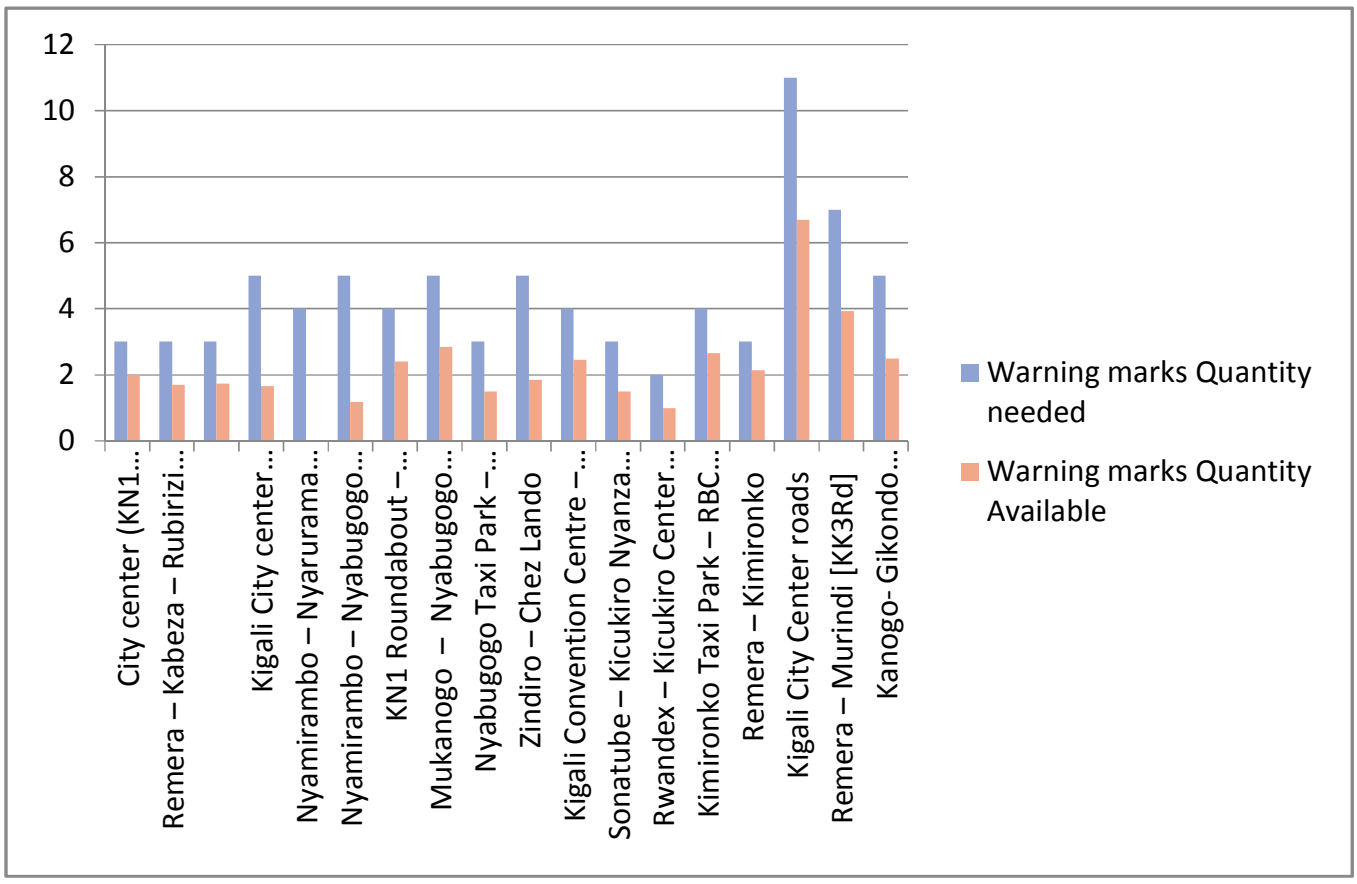

Figure 5: Comparison between Available and Needed Warning signs Facilities 


\subsection{Pedestrian Buses Shelter Facilities}

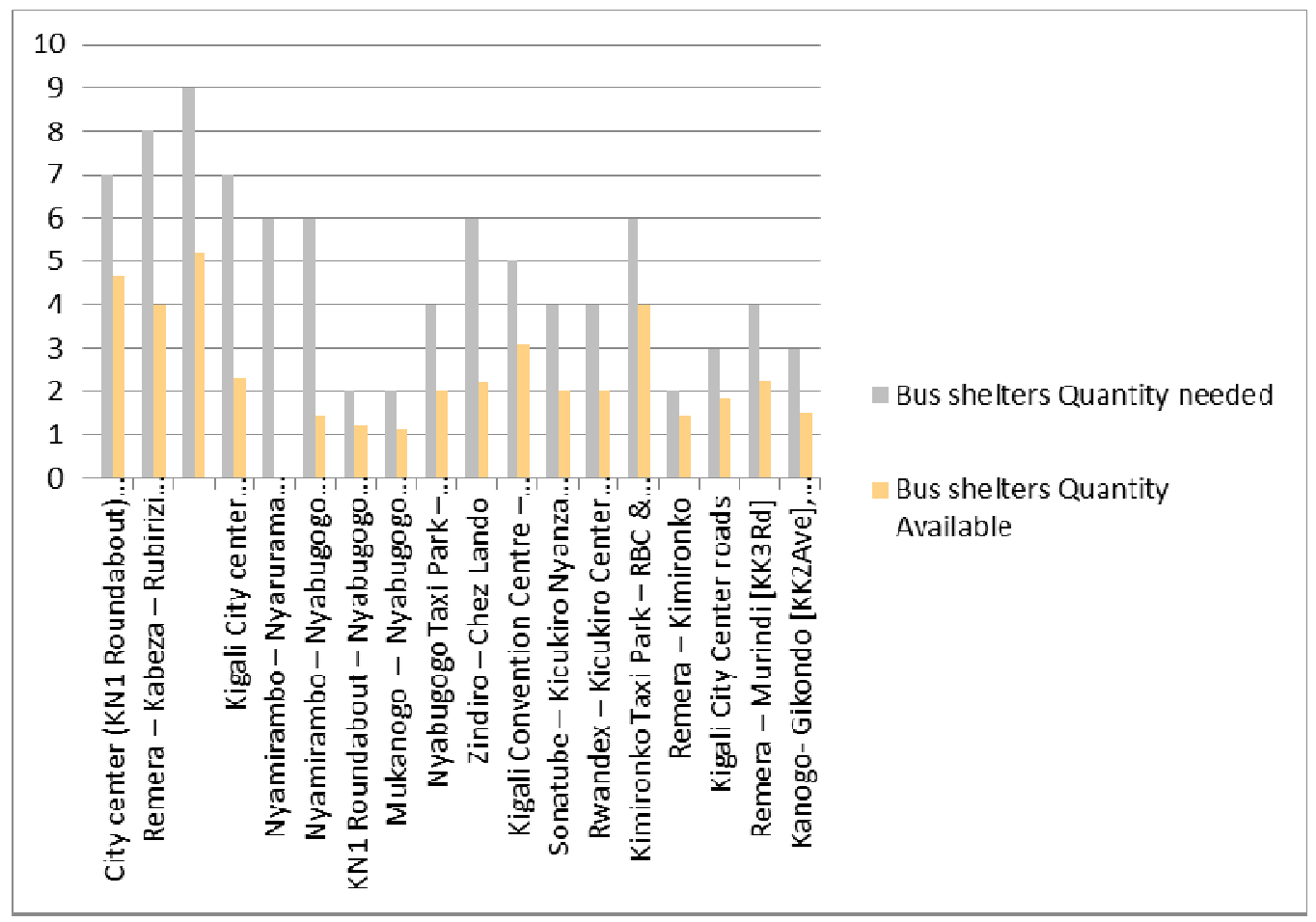

Figure 6: Comparison between Available and Needed pedestrian buses shelter facilities

\subsection{Pedestrian Pathways Facilities}

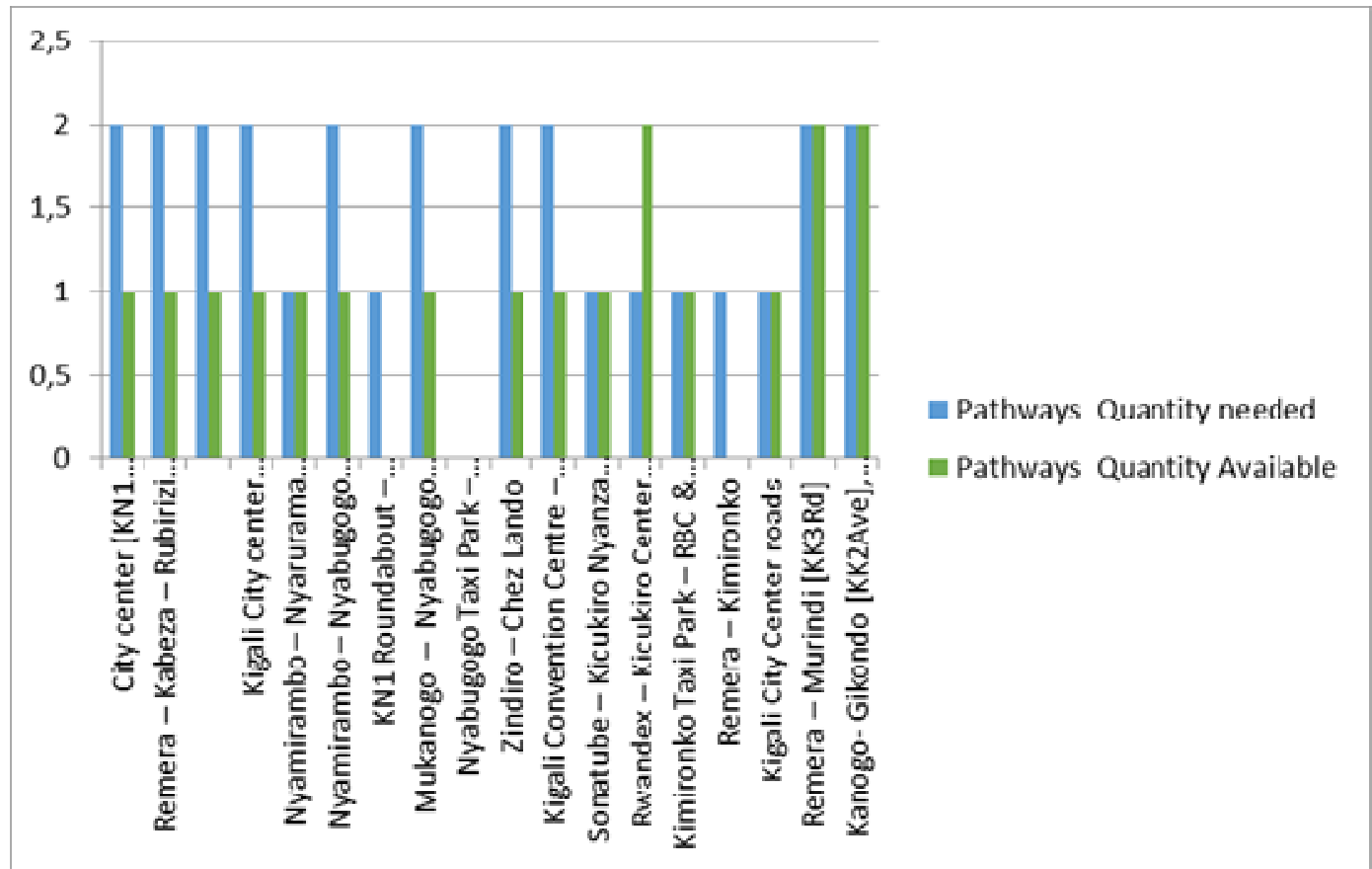

Figure 7: Comparison between Available and Needed Pedestrian Pathways Facilities 


\subsection{Pedestrian Public Stairs Facilities}

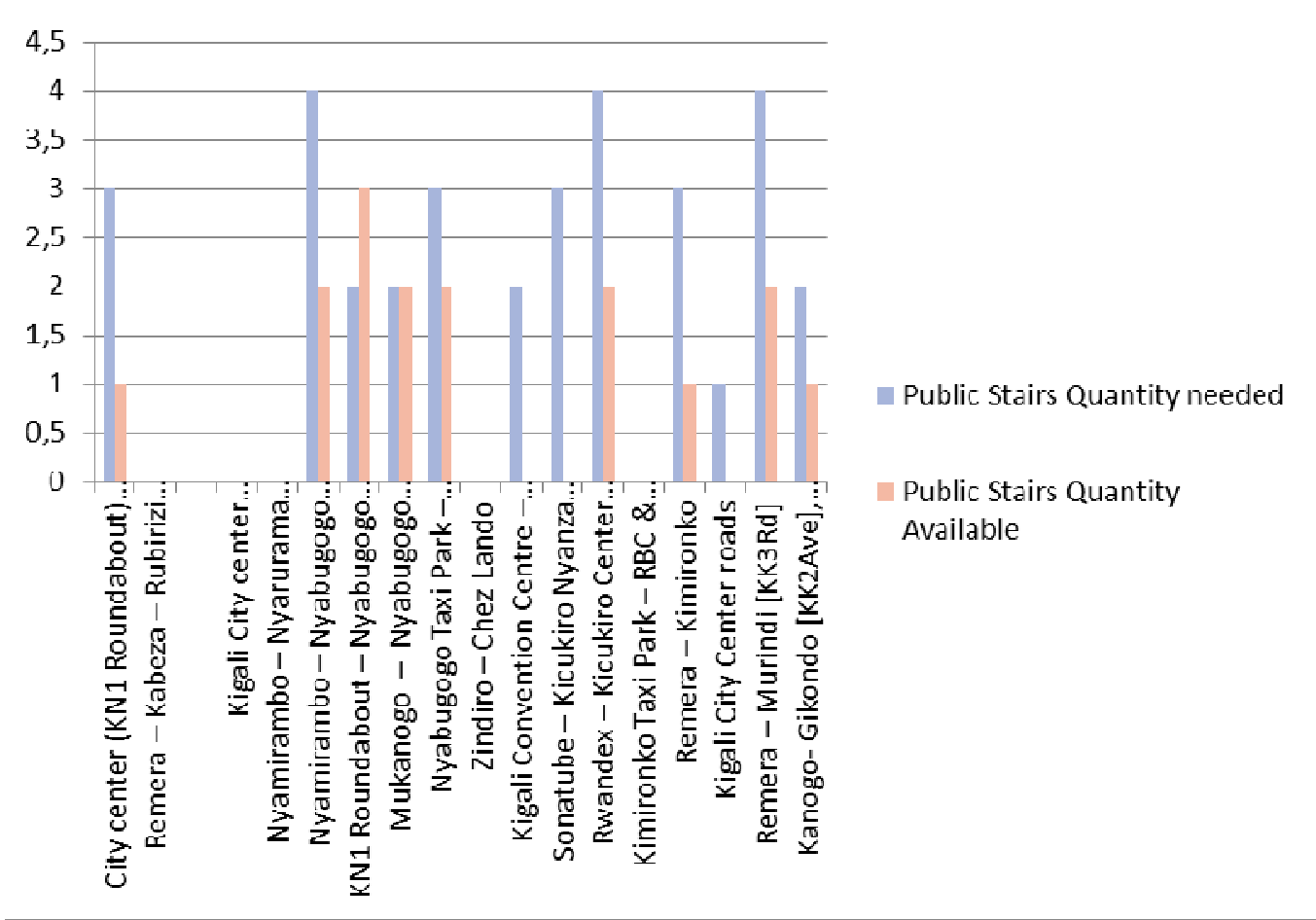

Figure 8: Comparison between Available and Needed Pedestrian Public Stairs Facilities

\section{DISCUSSION}

\subsection{Zebra Crossing Facilities}

From the field assessment on 18 visited road network, it was found that many of the needed crossing facilities for pedestrians are missing and this is dangerous to the their safety. The figure 9 below shows that only 120 facilities are available instead of 245 required as per the field findings.

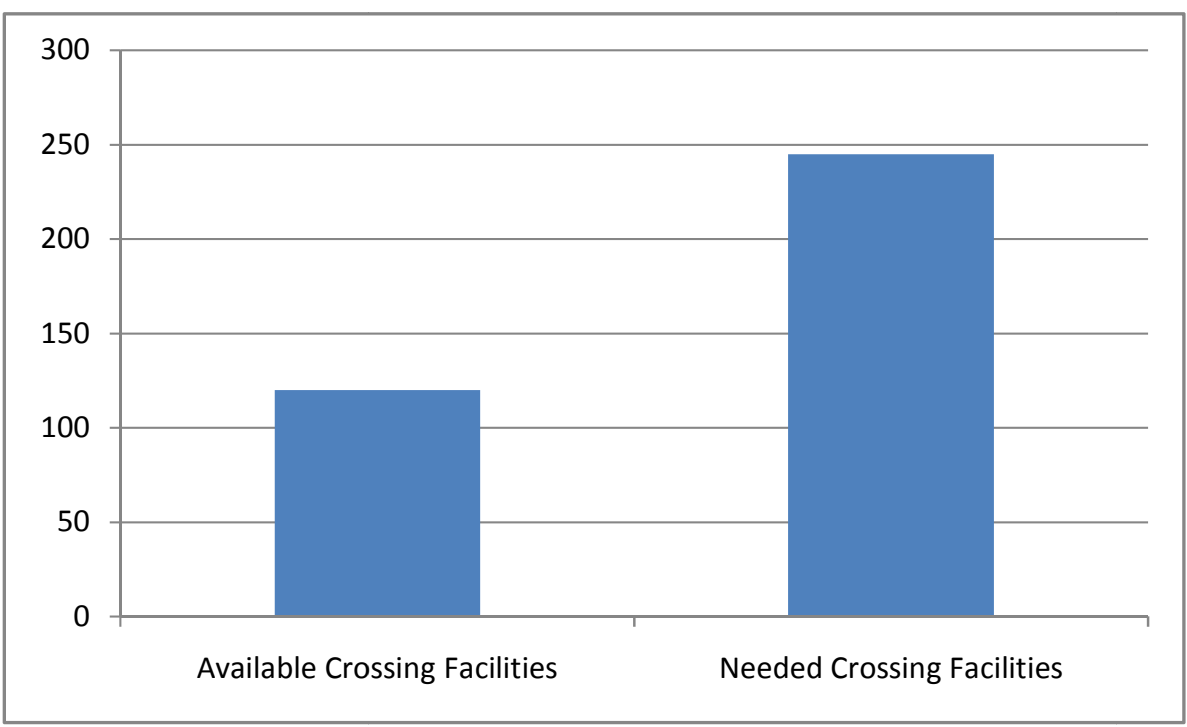

Figure 9: the available crossing vs the needed crossing facilities 

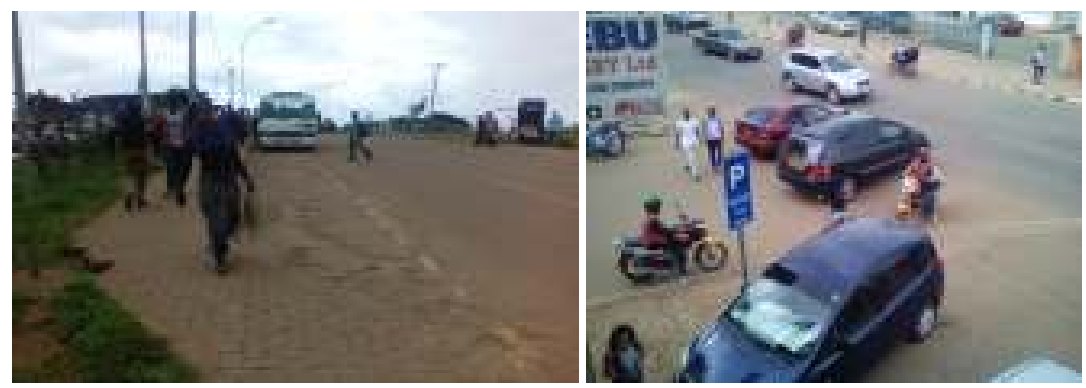

Figure 10: Some of the existing crossing without zebra painting and threat to pedestrians

\subsection{Traffic Lighting Facilities}

Also from the field assessment on 18 visited road network, it was found that the needed traffic lighting to facilitate pedestrians while crossing at junctions only 9 were available and installed out of 19 required to be installed as per the site and field visit data. Some of them 4 units were found not functioning at that time and needed repairs. Statistically computed results showed that only $47.4 \%$ of the traffic lighting facilities were implemented to help pedestrians to cross but still $44.4 \%$ of them are only reliable. So there is a need to increase these facilities and repair the ones out of service.

\subsection{Pedestrian Bridges (Overpass)}

During the assessment of pedestrian needs facilities in this paper, it was found that they are needed for some places like at KN1 Round About to Nyabugogo (KN8Ave \& KN1Rd) Network as an alternative of Zebra crossings, at KK2Ave \& KN68St on the leveled side as an alternative to the zebra crossing for they are located in danger zone.

\subsection{Warnings signs Facilities}

Warning signs are still very low on the road networks visited and it was found that almost $47 \%$ of the required are yet installed and this needs to be a priority so as to help pedestrians to escape from any road danger about their safety.
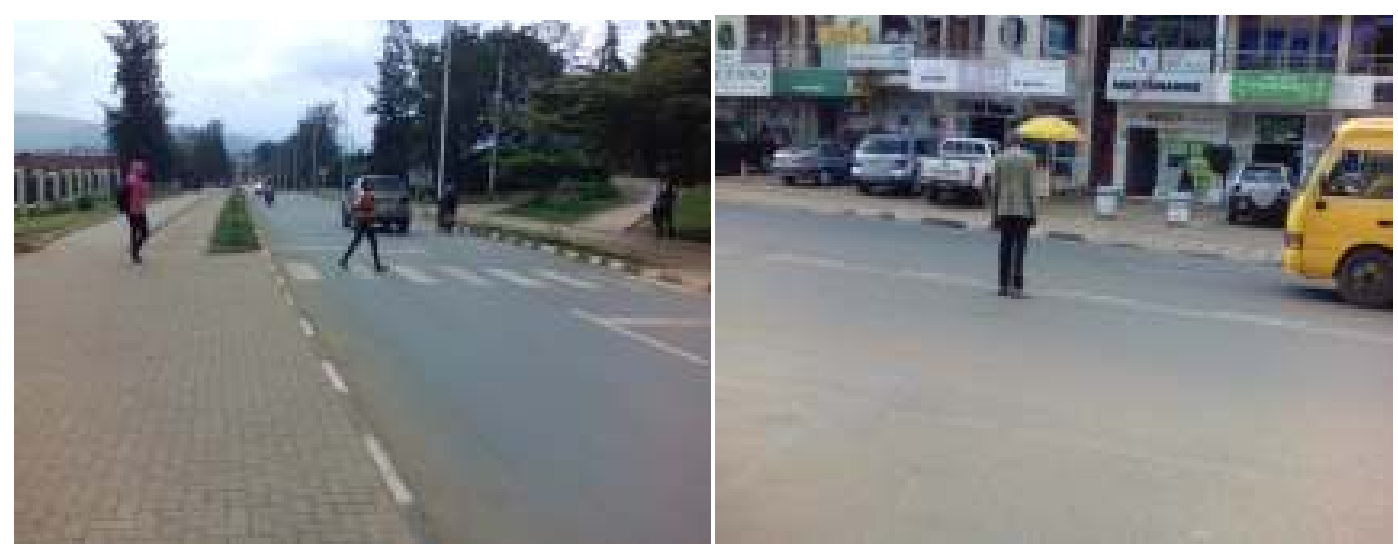

Figure 11: Zebra crossing without a warning sign (Left hand photo) on KG17Ave road and difficult/unsafe crossing at KN11Ave, Kimironko to Chez Lando (Right hand photo).

\subsection{Pedestrian Bus Shelters}

Those facilities are related to the bus stops; they are sometimes ignored during pedestrian facilities designs but they are needed for pedestrians' health for sun radiation and rainfall. Sunrays and rainfalls are the natural phenomena that pedestrians can't escape while he or she is using road for daily base activities or trip. It was found that generally out of the required around $35 \%$ are constructed and operational. Still a large number is to be added as soon as possible. The figure below illustrates some of the road networks lacking shelters for pedestrians. 


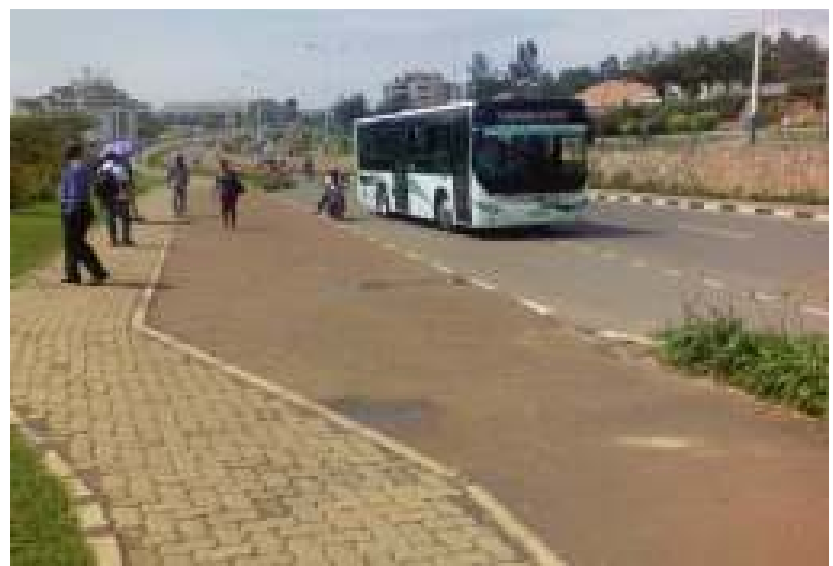

Figure 12: Bus stop without pedestrian shelter on KN501St

\subsection{Pedestrian Pathways}

Those facilities are mostly occurring beside the curved road or near the network from one sidewalk to another. They reduce the density of pedestrians near the networks and provide a comfort passage of pedestrians. They may be implemented where there is such possibility, but better if they are relatives to the Zebra crossings.

The paper found that around $67 \%$ of the required pedestrian pathways are built but still some of the road does not provide them and this is an encouraging indicator that in the near future the coverage is possible. Apart from the pedestrians pathways the escaping island are also useful for lanes separation and also for pedestrians to refresh while waiting for motor drivers to give a free way for him or her. They may be implemented in T-networks or junctions, on a wider crossover networks.

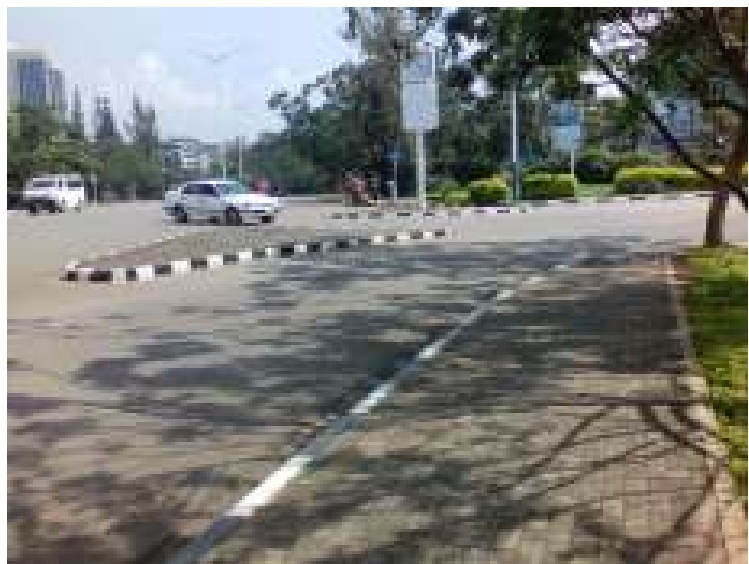

Figure 12 : escape island on a network of KG7Ave \& KG544St

\subsection{Public Stairs Facilities}

From the results, it was found that $48.5 \%$ of the required stair case facilities are provided and some are missing. Stairs which give pedestrians access to the roads need to have slip but rough staircase with a limited angle of elevation which is not adequate to physically challenged people were only found on the field. At least one side access should be designed to facilitate physically challenged people. 


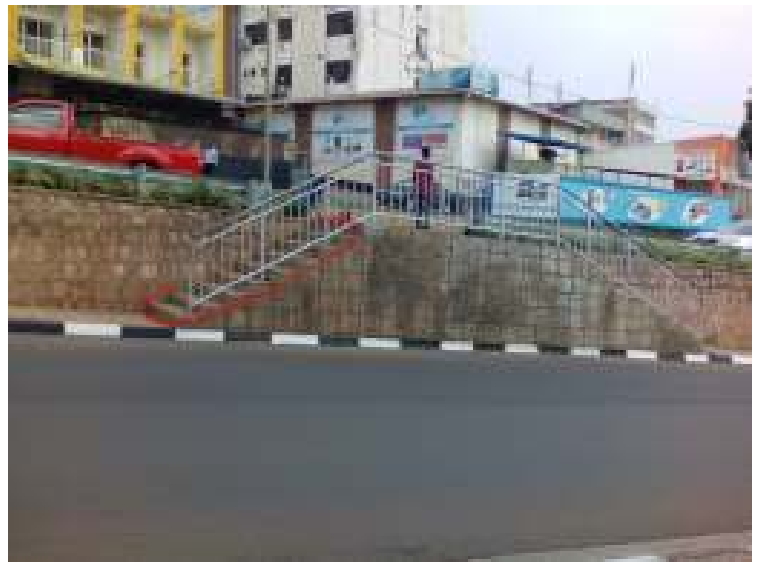

Figure 13: a stair case on KN1Rd built recently in 2019

\subsection{Other General Mobility Findings}

In the City of Kigali specifically the car free zone of Nyarugenge District, pedestrians are free to move and leisure; the zone like this is also needed in other Districts of Gasabo and Kicukiro of the city.

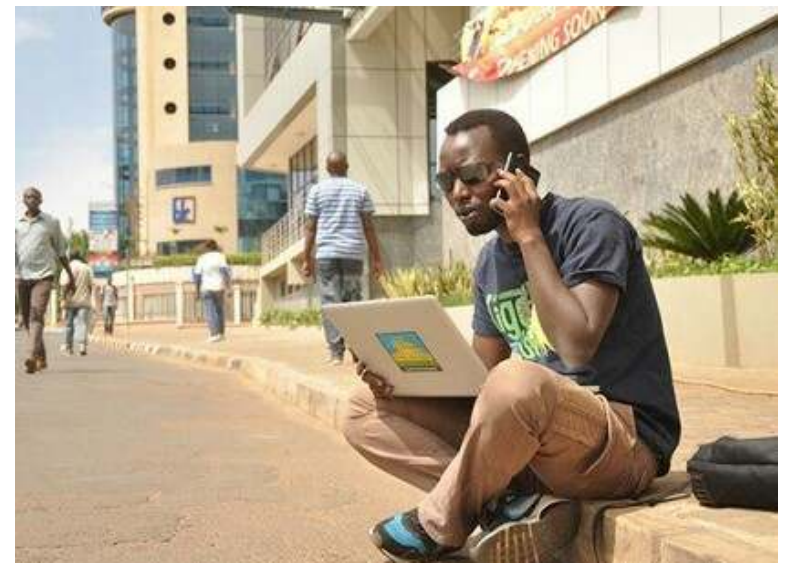

Figure 15: Car Free Zone of Nyarugenge District

Grade-separation of crossings is another excellent way to eliminate conflict between vulnerable road users and vehicles, but throughout the city, these infrastructures were not found. This must be encouraged in the near future for vey clouded zones of Nyabugogo, RemeraGiporoso and Kicukiro intersection area.

Lastly, it was observed that many of the pedestrians cross road network facilities while talking on their phone and this can reduce their level of safety. Every pedestrian should also know more about road safety measures to minimize the accidents. This can be achieved by displaying the road safety notices along and around the city corners where pedestrians are more likely to cross.

\section{CONCLUSION}

This paper looked on the major challenging matter for pedestrian mobility in The City of Kigali and found that according to the chronological order of gravity, the absence and inadequate traffic lighting facilities as the main first challenge, secondary by the inadequacy number and location of zebra crossing facilities, thirdly by the lack of enough sign posts, fourthly and lastly the challenging inadequate walkways, absence of pedestrian overpass bridges associated with the unavailable bus shelters for pedestrians.

Mariya et al. (2013) recommended for availing the basics needs and facilities of pedestrians as part of better urban transport infrastructure and this was found to be inadequate for the city of Kigali and must be implemented to solve the inadequacy and insufficient number of mentioned facilities that include traffic lights, 
overpass bridges and bus shelters. The City of Kigali's accidents were mostly found to occur at the places where pedestrians were crossing without marking or signing facilities; as per Zhuang and Wu (2011) crossing unmarked roadway contribute much to the traffic accidents and this must be looked at by the city authorities for better sustainability of the safety of pedestrians and the driver's awareness about the unusual road geometric parameters susceptible to trigger accidents such as sharp curves, locations of a high sequence of curves, high gradients and change of lane widths so as to reduce accidents is to be thought of because Kigali is a mountainous city with hills and Valleys with high gradients.

Lim (2008) stated that the speeds are related to pedestrian age for their physical, cognitive and psychosocial abilities to cross road network. It is necessary for the city authorities to control the speed by placing sign posts near the schools; markets, bus parking's, stadiums and other important city public infrastructures so as to allow the free mobility of the nearby people. Granie and Brenac (2014) pointed out about the pedestrian behavior of being strongly dependent on biological gender, and it has also been found to depend on the psychological masculinity of an individual. This behavior can be thought of by implementing some pedestrian overpass bridges in the selected zones of the city where a great number of pedestrians cross with various categories like at Kicukiro, Remera-Giporoso and Nyabugogo junctions.

\section{REFERENCES}

Ahmad, Abdullah and Mahesh, Srinath and Rastogi, Rajat., 2014. Selection of Roundabout Entry Capacity Model for Indian Condition. Urban Transport Journal. 13. 79-87.

Bonnes, M. and Bonaiuto, M., 2002. Environmental Psychology: From Spatial-Physical Environment to Sustainable Development. In: R. B. BECHTEL and A. CHURCHMAN, eds. HANDBOOK OF ENVIRONMENTAL PSYCHOLOGY. New York: John Wiley and Sons, Inc., pp. 28-54.
Charles 2010. Best way of teaching pedestrians, how to use road is to use communication design, from Rwanda Today: http://focus.rw .

Dulaski, D. M.; Liu, Y., 2013. Stepping off the Curb to Increase Drivers. Yielding Behavior at Mid-block Crosswalks. In Proceedings of the 92nd Transportation Research Board Annual meeting, Washington D.C., 1-13.

Dý'az, E. M., 2002. Theory of planned behavior and pedestrians' intentions to violate traffic regulations. Transportation Research Part F: Traffic Psychology and Behavior 5 (3), 169-175.

Groat, L. and Wang, D., 2002. Architectural Research Methods. New York: John Wiley and Sons INC.

Granie, M. A., Brenac, T., Montel, M.C., et al., 2014. Influence of built environment on pedestrian's crossing decision. Accident Analysis and Prevention 67 (1), 75-85.

Holland, Carol, Hill, Ross 2010. Gender differences in factors predicting unsafe crossing decisions in adult pedestrians across the lifespan: A simulation study., Accident Analysis and Prevention, 42(4), 1097- 1106.

Lim, E., 2008. Teaching Children to Walk Safely as They Grow and Develop:. media, b. (n.d). Understanding logo design. Bahrain.

Mariya Khatoon, Geetam Tiwari, Niladri Chatterjee, 2013. Binary Probabilistic Models for Pedestrians. Crossing Behavior and Risk at the Free Left Turn: Delhi, India. Proceedings of the Eastern Asia Society for Transportation Studies, Vol.9, 2013.

Marshall, C. and Rossman, G. B., 2006. 2006. Designing Qualitative Research. New York: SAGE Publications. 
Miller, G., Dingwall, R. and Morphy, E., 2004. Using Qualitative Data and Analysis. In D. Silverman, Qualitative Research: Theory, Method, and Practice (2nd ed., pp. 325-341). London: Sage Publications.

Neuman, L. W., 2006. Social Research Methods: Qualitative and Quantitative Approaches. New York: Pearson Education.

Tafahomi, R. and Nadi, R., 2016. Dehistoricisation the Urban Landscape through Transition of the Enclosure Ratio in Urban Fabric of Gonabad City in Iran. J Archit Eng Tech, Volume 5(Issue 2), pp. 1-6.
Tafahomi, R. and Nadi, R., 2020. Derivation of a Design Solution for the Conservation of a Historical Payab in the Redevelopment of Doloeei, Gonabad. International Journal of Built Environment and Sustainability, 7(1), pp. 1-9.

Peter Wright 2012, Advertising best tool in communication to promote pedestrians safety Dublin: Global Road Safety Partnership.

Zhuang and Wu 2011. Pedestrians. crossing behaviors and safety at unmarked roadway in China Accident Analysis and Prevention, 43 (6) 2011, pp.

1927-1936 